\title{
Comprehensive analysis of the regulatory roles of auxin in early transdifferentiation into xylem cells
}

\author{
Saiko Yoshida $\cdot$ Kuninori Iwamoto $\cdot$ \\ Taku Demura $\cdot$ Hiroo Fukuda
}

Received: 7 August 2008/Accepted: 13 March 2009/Published online: 27 March 2009

(C) Springer Science+Business Media B.V. 2009

\begin{abstract}
Auxin is essential for the formation of the vascular system. We previously reported that a polar auxin transport inhibitor, 1- $N$-naphthylphthalamic acid (NPA) decreased intracellular auxin levels and prevented tracheary element (TE) differentiation from isolated Zinnia mesophyll cells, but that additional auxin, 1-naphthaleneacetic acid (NAA) overcame this inhibition. To understand the role of auxin in gene regulation during TE differentiation, we performed microarray analysis of genes expressed in NPAtreated cells and NPA-NAA-treated cells. The systematic gene expression analysis revealed that NAA promoted the
\end{abstract}

The nucleotide sequence reported in this paper has been submitted to DDBJ/EMBL/GenBank Nucleotide Sequence Databases

(http://www.ddbj.nig.ac.jp/) under the following accession numbers: AB439582 (ZeCKX), AB477370 (ZePINa), AB477371 (ZePINb), AB477372 (ZePINc), AB477373 (ZePINd), AB477374 (ZePINe), AB477375 (ZeLAX1), AB477376 (ZeLAX2).

Electronic supplementary material The online version of this article (doi:10.1007/s11103-009-9485-y) contains supplementary material, which is available to authorized users.

S. Yoshida $(\varangle) \cdot$ K. Iwamoto $\cdot$ H. Fukuda $(\square)$

Department of Biological Sciences, Graduate School of Science,

The University of Tokyo, 7-3-1 Hongo, Bunkyo-ku,

Tokyo 113-0033, Japan

e-mail: saiko.yoshida@ips.unibe.ch

H. Fukuda

e-mail: fukuda@biol.s.u-tokyo.ac.jp

T. Demura

Plant Science Center, RIKEN, 1-7-22 Suehiro, Turumi-ku,

Yokohama-shi, Kanagawa 230-0043, Japan

Present Address:

S. Yoshida

Institute of Plant Sciences, University of Bern, Altenbergrain 21,

3013 Bern, Switzerland expression of genes related to auxin signaling and transcription factors that are known to be key regulators of differentiation of procambial and xylem precursor cells. NAA also promoted the expression of genes related to biosynthesis and metabolism of other plant hormones, such as cytokinin, gibberellin and brassinosteroid. Interestingly, detailed analysis showed that NAA rapidly induces the expression of auxin carrier gene homologues. It suggested a positive feedback loop for auxin-regulating vascular differentiation. Based on these results, we discuss the auxin function in early processes of transdifferentiation into TEs.

Keywords Auxin - Microarray - NPA .

Tracheary element differentiation $\cdot$ Zinnia elegans

$\begin{array}{ll}\text { Abbreviations } \\ \text { ABA } & \text { Abscisic acid } \\ \text { BL } & \text { Brassinolide } \\ \text { BR } & \text { Brassinosteroid } \\ \text { CT } & \text { Cathasterone } \\ \text { CS } & \text { Castasterone } \\ \text { 6-DeoxoCT } & \text { 6-Deoxocathasterone } \\ \text { DMSO } & \text { Dimethyl sulfoxide } \\ \text { DR5 } & \text { Synthetic auxin-inducible promoter } \\ \text { IAA } & \text { Indole-3-acetic acid } \\ \text { JA } & \text { Jasmonic acid } \\ \text { NAA } & \text { 1-Naphthaleneacetic acid } \\ \text { NPA } & \text { 1- } N \text {-Naphthylphthalamic acid } \\ \text { TE } & \text { Tracheary element }\end{array}$

\section{Introduction}

The plant hormone auxin is an essential regulator of plant growth and development. The principal auxin, indole-3- 
acetic acid (IAA), is synthesized in the shoot apex and transported to the root tip. At a cellular level, auxin is incorporated by both diffusion and influx carriers such as AUX1 protein, and directional auxin transport is primarily controlled by an efflux carrier complex that is characterized by the PIN family proteins (Teale et al. 2006). Polarized auxin transport provides essential directional and positional information for developmental processes, such as apical dominance, organ development, tropic growth, and vascular development (Benkova et al. 2003; Blancaflor and Masson 2003; Blilou et al. 2005; Klee and Estelle 1991).

Polar auxin transport is believed to function in the formation of a continuous vascular strand. It is known that local application of IAA induces vascular strand formation (Sachs 1981). IAA application can define the site of vascular differentiation, and a new functional vascular strand will extend basally from locally applied IAA. On the other hand, disruption of directional auxin movement by gene mutations (pin-formed 1 etc.) or by treatment with auxin transport inhibitors, such as 1-N-naphthylphthalamic acid (NPA), results in severe developmental defects. NPA causes ectopic vascular differentiation at leaf margins, and also produces parallel vascular strands at the central regions in a similar fashion to the phenotypes of the pinl mutant (Mattsson et al. 1999, 2003; Sieburth 1999; Berleth and Mattsson 2000; Berleth et al. 2000; Wenzel et al. 2008). These results suggest that polar auxin transport inhibitors disrupt auxin flow and accumulate auxin at the leaf margin, resulting in ectopic vascular differentiation (Mattsson et al. 1999).

Most of these data are consistent with the auxin flow canalization hypothesis proposed by Sachs (1991): auxin flow, starting initially with diffusion, induces the formation of the polar auxin transport cell system, which in turn promotes auxin transport and leads to canalization of auxin flow along a narrow file of cells. This file of cells differentiates into a strand of procambial cells, and eventually into strands of various vascular cells. However, the molecular mechanism by which auxin flow promotes vascular differentiation still remains elusive.

Auxin is transported not only within the vasculature, but also within the other tissues. In the shoot apical meristem, AUX1 protein is localized in the external L1 layer of the meristem and in the abaxial epidermis of the developing primordia. PIN1 protein is also localized primarily in the cells of the L1 layer, but it is restricted intracellularly to the membrane facing the leaf primordia. Auxin can be expected to flow in these cells and may induce the formation of primordia (Reinhardt et al. 2003). In the root tip, AUX1 protein and PIN family proteins also control growth and gravitropism (Blilou et al. 2005; Leyser 2005; Friml 2003). AUX1 is localized in the epidermis and collumella cells in the root apex. PIN family proteins localize not only in the vascular cells but also in various kinds of other cells: epidermis, cortex, stele, cortical cells, columella cells, the lateral side of pericycle, and the quiescent center (Blilou et al. 2005). These auxin carriers may promote auxin accumulation in the columella, following a gravity stimulus. Auxin is released asymmetrically from columella cells and transported from the apex via the lateral root cap and epidermal cells and then redirected to the apex via the stele. Despite the auxin flow in these cells, they never differentiate into vascular cells. These results suggest that auxin flow is not enough to promote vascular differentiation and that other factor(s) induced by auxin flow in vasculature forming tissues plays a role in vascular differentiation. These considerations raise the following questions: what happens in cells potent to differentiate to vascular tissue after changes in auxin flow? How does auxin induce the differentiation of vascular cells such as procambial cells?

Fukuda and Komamine (1980) reported that single mesophyll cells isolated from Zinnia leaves in the presence of auxin and cytokinin, transdifferentiate into tracheary elements (TEs). A detailed analysis of the transdifferentiation process revealed three distinctive stages (Fukuda 1997, 2004). Stage 1 corresponds to a functional dedifferentiation process from isolated mesophyll cells. At stage 2 , dedifferentiated cells may differentiate into procambial cells, and then into xylem cell precursors. At stage 3, the differentiation of TEs occurs from xylem precursor cells (Yamamoto et al. 1997, 2001).

This Zinnia system facilitates the analysis at of the mechanisms of xylogenesis at the cellular levels. Using this system, various factors such as plant hormones, peptides and genes involved in TE differentiation were studied. During stage 2, a unique arabinogalactan protein, xylogen, mediates inductive cell-cell interaction in vascular development (Motose et al. 2004). Brassinosteroids, which are also synthesized actively during stage 2 , initiate the entry into stage 3 (Yamamoto et al. 1997, 2001). In contrast, a dodecapeptide of the CLV3/ESR-related (CLE) family, TDIF suppressed the entry into stage 3 (Ito et al. 2006). Demura et al. (2002) performed a comprehensive microarray analysis of gene expression during xylogenesis. It describes the unique gene expression patterns during xylogenesis and a number of developmental stage-specific genes. The accumulated information has made Zinnia culture an excellent system for the analysis of auxin function at the cellular level, and it allows identifying the auxin-regulated master genes that control transdifferentiation into vascular cells.

In the Zinnia culture system, we have previously investigated the effects of auxin transport inhibitors on vascular cell differentiation and auxin metabolism (Yoshida et al. 2005). Our data clearly indicated that the inhibitors caused the decrease in intracellular free auxin level, through the promotion of auxin conjugates, and in 
turn the inhibition of TE differentiation. We also indicated that free NAA depletion may suppress the early process of transdifferentiation into TEs. The inhibitory effect of NPA was reversibly overcome by high concentration of auxin, which indicates that auxin promotes the initiation of xylogenesis. The use of both NPA and NAA allows the control of cultured cells synchronous entry into the differentiation process and therefore the analysis of the early process of transdifferentiation at the molecular levels.

Based on these results, we performed microarray analysis of genes expressed in NPA and/or NAA-treated cells, to get an insight into the effect of NPA and/or NAA on differentiation stage progression and NAA-dependent regulation of transdifferentiation process at molecular levels. Our results confirmed that NPA represses TE differentiation at the transition from stage 1 to 2 . Additional auxin overcomes NPA-dependent inhibition of TE formation by promoting termination of stage 1 and progression of stage 2. We also found that NAA promoted the expression of specific genes related to auxin signaling hormone biosynthesis, hormone metabolism, transcription and transport at the early stage of transdifferentiation. In particular, NAA rapidly induced the expression of auxin influx and efflux carrier genes. Finally, based on these results, we discuss the regulatory roles of auxin in the early process of transdifferentiation into TEs. We describe a model in which the molecular mechanisms of TE differentiation are controlled with the auxin canalization hypothesis.

\section{Materials and methods}

\section{Reagents}

NPA (Tokyo Kasei Kogyo Ltd Tokyo, Japan), NAA (Kanto Chemical, Tokyo, Japan), and IAA (Wako Pure Chemical Industry) were dissolved in dimethyl sulfoxide (DMSO, Wako Pure Chemical Industry) as stock solutions, stored at $-20^{\circ} \mathrm{C}$, and added to cultures at appropriate concentrations. Unless otherwise specified, they were added to the medium at the initiation of the culture. In the medium, final concentrations of DMSO were less than $0.5 \%(\mathrm{v} / \mathrm{v})$ in all samples, and this concentration does not affect TE differentiation or cell division (Fukuda and Komamine 1981).

\section{Cell culture}

The first leaves of 14-day-old seedlings of Zinnia elegans L. cv. Canary Bird (Takii Shubyo, Kyoto, Japan) were used as source material for the isolation of mesophyll cells in suspension culture according to the method of Fukuda and Komamine (1980). Cell culture was carried out according to Fukuda and Komamine (1982) and suspended at a cell density of approximately $8 \times 10^{4}$ cells $/ \mathrm{ml}$. The culture medium for the induction of TE differentiation (D medium) contained $0.54 \mu \mathrm{M}$ NAA and $0.89 \mu \mathrm{M}$ 6-benzyladenine (BA). For control cultures, in which no TEs were differentiated, $\mathrm{C}_{\mathrm{B}}$ medium that contained only $\mathrm{BA}$ as a phytohormone was used. Cells were cultured in the dark at $27^{\circ} \mathrm{C}$, rotating at $10 \mathrm{rpm}$ on a revolving drum. The frequencies of $\mathrm{TE}$ formation (\%) were determined as the number of TEs per number of living cells plus TEs. The frequencies of cell division (\%) were determined as the number of divided cells per number of living cells plus TEs. The number of cells was counted in three samples under a microscope, and at least 500 cells were examined in each sample.

cDNA microarray analysis

A total of 9,120 cDNA clones including marker genes for each stage of transdifferentiation and some known Zinnia genes were amplified by PCR and spotted on glass slides, as described in Demura et al. (2002). The Cy5-labeled cDNA population was generated using the mRNA fraction prepared from NPA or NPA plus DMSO/NAA-treated Zinnia cultured cells which had been collected at indicated times (see Fig. 1b, c). Poly (A) ${ }^{+}$RNA was extracted with a FastTrack 2.0 Kit (Invitrogen). A Cy3-labeled oligonucleotide was prepared for quantitation of each spotted cDNA. The sequence of this oligonucleotide was complementary to the amplified vector part common to all PCR products, which enabled the oligonucleotide to hybridize all spots in a cDNA quantity-dependent manner.

Fluorescent probe preparation and hybridization were performed as described in Yazaki et al. (2000). Hybridization was carried out after mixing the Cy5-labeled cDNAs and Cy3-labeled oligonucleotides. Signals of both Cy3 and Cy5 fluorescence were recorded and quantified.

Normalization was performed as described in Demura et al. (2002). After the normalization, only genes showing a signal value $>100$ through $\mathrm{Cy} 3$ channels were selected. These selected genes were analyzed for hierarchical clustering using the "Clustering Gene Tree" function with the "Measure Similarity by Standard Correlation" in GeneSpring. In the microarray experiment to examine the NAAdependent recovery of TE formation from NPA-mediated inhibition, genes that can meet all of the following criteria were selected as NAA-up-regulated genes: (1) genes showing a Cy 3 signal value $>50,(2)$ genes showing a Cy5 signal value $>50$, (3) genes showing within threefold difference in Cy5 values for replicates, (4) genes showing an average at least twofold increase in expression as compared to the negative control (cultures with $20 \mu \mathrm{M}$ NPA only), and (5) genes showing an average of at least twofold up-regulation in the time course of NAA-dependent recovery. 
Fig. 1 Effects of NPA and NAA on expression patterns of the 523 genes categorized into six groups by Demura et al. (2002). a Average expression patterns of group A-F genes of cells cultured in D-medium (From Demura et al. 2002). b Gene expression profiles of group $A-F$ in NPA-treated cells. c Gene expression profiles of group $A-F$ in cells cultured with only NPA (NPA + DMSO) and NPA plus NAA (NPA + NAA) The color scale indicates the expression levels

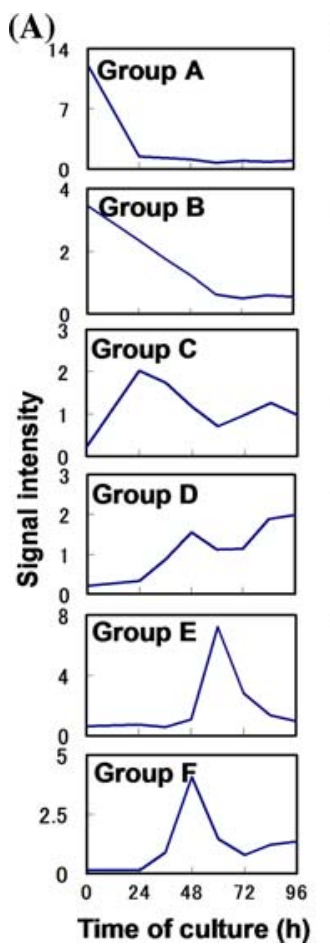

(B)

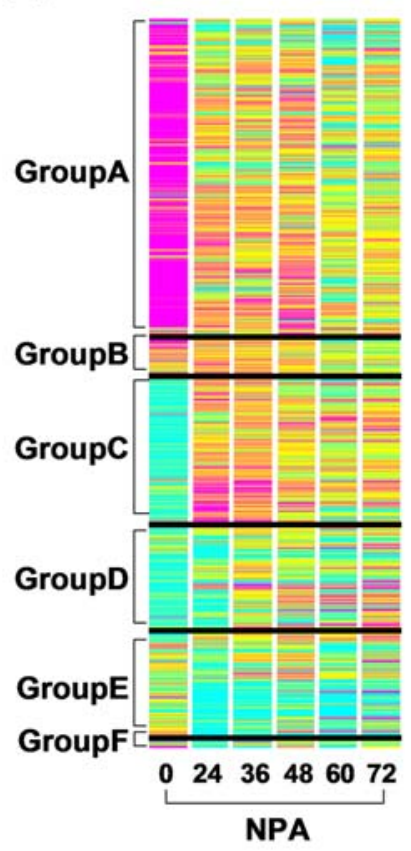

(C)

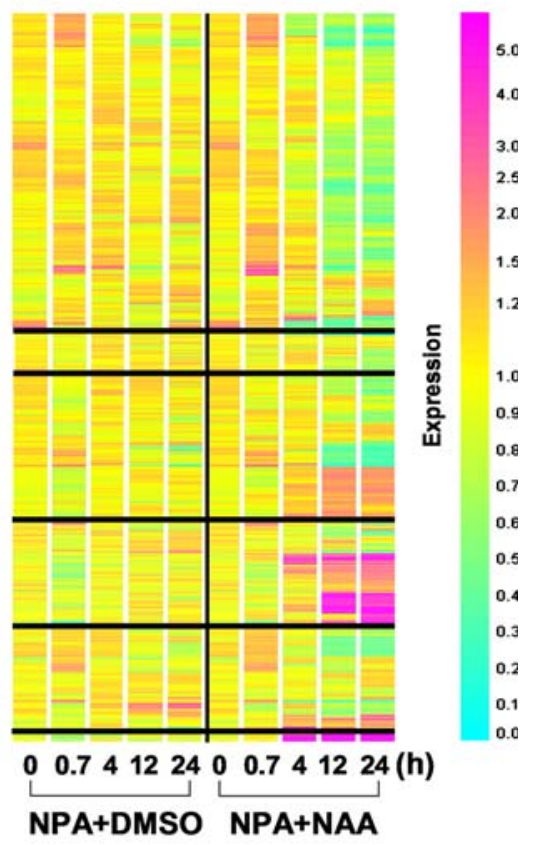

In Zinnia microarray system, all cDNA was spotted in duplicate. Microarray analyses of NPA-treated cells (0, 24, $36,48,60$ and $72 \mathrm{~h}$ ) and NPA plus DMSO/NAA-treated cells $(0,0.7,4$ and $12 \mathrm{~h})$ were performed twice. For the confirmation of reproducibility, Pearson's correlation coefficient values were calculated by using data normalized by median. These values were $>0.7820$ in microarray of NPA-treated cells and $>0.9118$ in microarray of NPA plus DMSO/NAA-treated cells, which indicated that the result is reliable. The raw microarray data can be found in the Supplemental Tables 6 and 7.

Database search and isolation of Zinnia cytokinin oxidase, PIN and AUXI homologues

Partial sequences of one cytokinin oxidase (CKX), five PIN, and two AUXI homologues were obtained from Zinnia EST databases by BLAST analyses. Full-length cDNA sequences of $C K X, P I N$, and AUXI-like genes were isolated using $5^{\prime}$ and $3^{\prime}$ rapid amplification of cDNA ends (RACE) with primers shown in Supplemental Table 1. Total RNA of Zinnia cells cultured for 36 or $60 \mathrm{~h}$ in D medium was extracted with Plant RNA Isolation Reagent (Invitrogen) and purified with RNeasy minicolumns (QIAGEN) according to the manufacturers' instructions. For 5' RACE, first strand cDNA synthesis was performed using a genespecific reverse primer and SuperScript III reverse transcriptase (Invitrogen), followed by the digestion of RNA template with $\mathrm{RNaseH}$ and the tailing of polyC to the $3^{\prime}$ end of cDNA with terminal deoxynucleotidyl transferase. The first PCR using the cDNA as templates were performed with an adapter primer linked to oligo $\mathrm{dG} / \mathrm{dI}$ and a gene-specific primer. The second and third PCRs were performed with another gene-specific primer and an adapter primer using the former PCR product as templates. For $3^{\prime}$ RACE, first strand cDNA synthesis was performed on total RNA using an adapter primer linked to oligo dT. The first PCR using the cDNA as templates was performed with an adapter primer and a gene-specific primer. The second PCR was performed with the adapter primer and another gene-specific primer using the first PCR product as a template. Amplified cDNAs by $5^{\prime}$ and $3^{\prime}$ RACEs were cloned into pGEM-T Easy vector (Promega, Madison, WI, USA) and sequenced. The fulllength cDNA sequences were assembled from overlapping sequences and named ZeCKX (Z4008, AB439582), ZeLAX1 (Z 3936, AB477375), ZeLAX2 (Z4786, AB477376), ZePINa (AB477370), ZePINb (AB477371), ZePINc (AB477372), ZePINd (AB477373), and ZePINe (AB477374). The deduced amino acid sequences of the ZeCKX, ZePINs, and ZeLAXs were aligned with other sequences taken from the GenBank and the Arabidopsis Information Resourse. The ClustalX 2.0 program was used for alignment and tree construction. The phylogenetic trees were displayed using Njplot software.

\section{Quantitative real-time PCR analysis}

Total RNA was prerared from Zinnia cultured cells by SDS phenol method (Ozeki et al. 1990), followed by DNase treatment and purification using RNeasy Plant Mini Kit 
(QIAGEN). After reverse transcription with oligo (dT)20 primer and SuperScript III reverse transcriptase, quantitative real-time PCR was performed using LightCycler 480 Instrument (Roche diagnostics) with LightCycler 480 Probes Master and universal ProbeLibrary probes in combination with gene-specific primers designed by ProbeFinder software (http://www.roche-applied-science. com; Supplemental Table 1). In addition to ZePINs and ZeLAXs, quantitative real-time PCR analysis for ZeTUA5 gene was performed as a control. Quantification of gene expression was performed by LighCycler software, and relative expression value to ZeTUA5 was calculated, respectively.

\section{Histochemical detection of GUS activity}

AtCKX1::GUS and AtCKX6::GUS transgenic lines were provided by Professor Thomas Schmülling (Free University of Berlin, Germany; Werner et al. 2003). For observations of $G U S$ staining patterns of AtCKX1::GUS and AtCKX6::GUS lines, liquid cultured, 3-days-old seedlings were used. These seedlings were treated with $10 \mu \mathrm{M}$ IAA for $6 \mathrm{~h}$ in a liquid medium. For GUS activity detection, samples were incubated at $37^{\circ} \mathrm{C}$ for $16 \mathrm{~h}$ in GUS staining buffer (100 mM phosphate buffer, $\mathrm{pH} 7.0,0.1 \%$ Triton X-100, 0.5 mg ml-1,5-bromo-4-chloro-3-indolyl- $\beta$ glucuronic acid, $0.5 \mathrm{mM}$ potassium ferricyanide, $0.5 \mathrm{mM}$ potassium ferrocyanide and $10 \mathrm{mM}$ EDTA) and rinsed in $70 \%$ ethanol. The samples were cleared in chloral hydrate: water: glycerol $(8: 2: 1, \mathrm{v} / \mathrm{v})$, and then observed under a microscope (Olympus, Japan).

\section{Results}

Effects of NPA on stage progression of TE differentiation

In an earlier study we found that NPA leads to auxin depletion, which in turn prevents the progression of TE differentiation in Zinnia cultures (Yoshida et al. 2005). To identify the molecular basis of the NPA inhibition, we performed microarray analyses with Zinnia cells cultured in the presence of NPA, using a previously prepared cDNA chip (Demura et al. 2002), in which 523 cDNAs showed an eightfold change in expression over the transdifferentiation time-course in differentiation-induced cell culture (D-culture) and were clustered into 6 groups (Fig. 1a, groupA-F). The expression patterns of these 523 cDNAs are highly reproducible in any culture. Therefore, we compared the gene expression pattern of NPA-treated cells with the pattern described for D-cultures (Demura et al. 2002).
In NPA-treated cells, the expression of the A and B group genes, which peak at the start or within 12-24 h (stage 1) of the differentiation-induced culture (Fig. 1a), was high even at 36 or $48 \mathrm{~h}$ (Fig. 1b; Supplemental Table 2). The $\mathrm{C}$ group genes were expressed highly between 24 and $48 \mathrm{~h}$. In contrast, the expression of most D, $\mathrm{E}$, and $\mathrm{F}$ group genes, which were up-regulated during stage 2 and/or 3, was repressed by the addition of NPA (Fig. 1b; Supplemental Table 2). These results strongly suggest that NPA suppresses the entry into stage 2 of xylem differentiation and rather enhances stage 1 related events.

Effects of NAA on NPA-dependent suppression of stage progression

Previous study showed that NAA overcomes NPA-induced suppression of TE formation with a delay, which corresponds roughly to the delay of NAA addition after NPA treatment, whenever NAA is added before $96 \mathrm{~h}$ of culture (Yoshida et al. 2005). Based on this result, we designed an experiment to understand molecular events underlying auxin-initiated TE differentiation. It has been known that stage 1 involves down-regulation of many wound-induced genes, which are up-regulated by cell isolation (Demura et al. 2002). To avoid changes in gene expression due to wound response, all of which are auxin independent, we used Zinnia cells that had been cultured for $60 \mathrm{~h}$ in the presence of NPA and examined gene expression shortly after NAA treatment.

As a result, in contrast to the gene expression profile of NPA treated culture cells, NAA-treatment repressed most of the $\mathrm{A}, \mathrm{B}$, and $\mathrm{C}$ group genes within 4 or $12 \mathrm{~h}$ after NAA addition. On the other hand, NAA promoted expression of the $\mathrm{D}$ and $\mathrm{F}$ group genes $4 \mathrm{~h}$ after its addition. The addition of NAA to NPA-treated cells induced the expression of some of the E group genes $12 \mathrm{~h}$ after addition (Fig. 1c). Overall, these results indicate that NAA restarts the program that NPA has arrested, that is, both stage 1 termination and stage 2 progression.

\section{Characterization of NAA-up-regulated genes}

Of about 9,000 cDNAs on our Zinnia microarray, 149 cDNAs were up-regulated significantly ( $>$ twofold) after $0.7 \mathrm{~h}$ and/or $4 \mathrm{~h}$ of NAA addition (Supplemental Table 3). The expression of these genes is anticipated to be regulated by auxin-induced transcription machinery. Therefore, we tried to identify cDNAs encoding transcription-related proteins that were up-regulated rapidly by NAA treatment and found 18 cDNAs (Supplemental Fig. 1; Supplemental Table 4). Interestingly, among those cDNAs, Z567, 
$\mathrm{ZeHB1Om}$, and ZeHB13 (Z3685), which are known as key transcription factors of vascular differentiation (Kubo et al. 2005; Ohashi-Ito et al. 2002, 2005) were strongly expressed after $4 \mathrm{~h}$ of NAA addition (Supplemental Fig. 1).

To examine whether these NAA-up-regulated genes are involved in transdifferentiation or not, the auxin responsiveness of these genes was examined in the public microarray database of wild-type Arabidopsis seedlings which were treated with IAA for $30 \mathrm{~min}, 1$ and $3 \mathrm{~h}$ (TAIR submission number: ME00336, IAA time course in wildtype seedling). About 91 Arabidopsis genes were selected as homologous genes for 149 Zinnia cDNAs. Of them, 86 genes were available in public databases, in which 16 genes (19\%) were up-regulated (>twofold), but 65 genes (75\%) showed no change and five genes $(6 \%)$ were downregulated ( $>$ twofold) after the IAA application (Supplemental Table 3). This result suggests that NAA upregulated genes identified on the Zinnia microarray are not simply induced by auxin, but may be induced by auxin in a vascular cell-related manner.

Expression profiles of auxin-related gene homologues

To get an idea of the molecular mechanisms of NAA-initiated TE differentiation, we examined in detail the expression profiles of auxin-related gene homologues (Fig. 2; Supplemental Table 5). The Aux/IAA proteins and the auxin response factors (ARFs), are key regulators of auxin-modulated gene expression (Abel and Theologis 1996; Hagen and Guilfoyle 2002; Liscum and Reed 2002) This Zinnia microarray contained five cDNAs with similarities to a class of auxin early response genes, Aux/IAAs. Four of them (Z824, Z1689, Z3615, and Z2172) started being expressed $0.7 \mathrm{~h}$ after NAA addition, while Z5079 was not induced significantly by NAA treatment (Fig. 2). Most ARF homologues were up-regulated in response to NAA treatment (Fig. 2). In particular, the expression of Z8416, Z1496, and Z3670 was increased as early as $4 \mathrm{~h}$ after NAA addition. Other genes, including BIGs and TIRs (Gil et al. 2001; Dharmasiri et al. 2005) did not show a remarkable change after NAA treatment, except Z4733 and Z464 (Fig. 2). Z4733 and Z464, which have similarities with IAA-alanine resistance protein 1 (IARI) involved in IAA homeostasis (Lasswell et al. 2000), were up-regulated by NAA addition.

Expression analysis of Zinnia auxin carrier homologues

Our microarray contained two cDNAs (Z3936 and Z4786) with similar to Arabidopsis AUX1. These genes were upregulated after $4 \mathrm{~h}$ of NAA addition (Fig. 2), suggesting that auxin activates auxin influx.

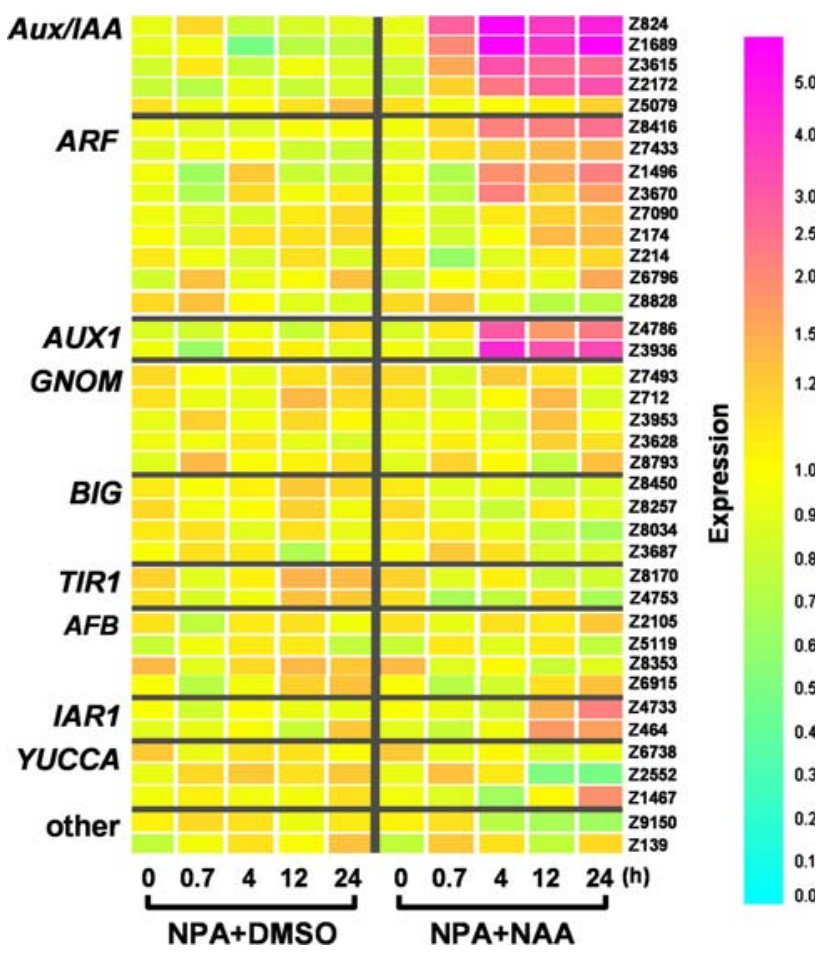

Fig. 2 Expression profiles of auxin-related genes homologue. Gene expression patterns of auxin-related gene homologues in cells cultured with only NPA (NPA + DMSO) or NPA plus NAA (NPA + NAA). The color scale indicates the expression levels. The results of BLASTX search of each clone against Arabidopsis database are shown in Supplemental Table 5

Because, unfortunately, cDNAs for auxin efflux carriers did not reside on Zinnia microarray, we tried to isolate PIN homologues from a Zinnia cDNA library. As a result, we succeeded in isolation of full length of cDNAs for five different Zinnia PIN homologues, ZePINa, ZePINb, ZePINc, ZePINd and ZePINe. ZePINa, ZePINb and ZePINc were quite similar to Arabidopsis PIN1. ZePINd, and ZePINe were similar to Arabidopsis PIN3/PIN4/PIN7 (Fig. 3a). We also isolated full length cDNA sequences of the two AUX1 homologues, and named ZeLAX1 (Zinnialike AUX1 gene1) (Z3936) and ZeLAX2 (Z4786) (Fig. 3b).

Using these ZePIN cDNAs together with two ZeLAX cDNAs, we performed quantitative RT-PCR. The transcripts for all these cDNAs increased at $60 \mathrm{~h}$ of culture and NPA suppressed this increase (Fig. 4a-g). The feeding of NAA to NPA-treated Zinnia cells induced increase in transcripts for ZeLAX1 and ZeLAX2 at 4 and $12 \mathrm{~h}$, which confirmed microarray data. Similarly, transcripts for ZeP$I N a, Z e P I N b, Z e P I N d$, and ZePINe were up-regulated by NAA at 4 and $12 \mathrm{~h}$, although transcript for ZePINc increased not only by NAA but also by DMSO treatment. These results clearly indicate that auxin up-regulates transcript levels of both auxin influx and efflux carries. 


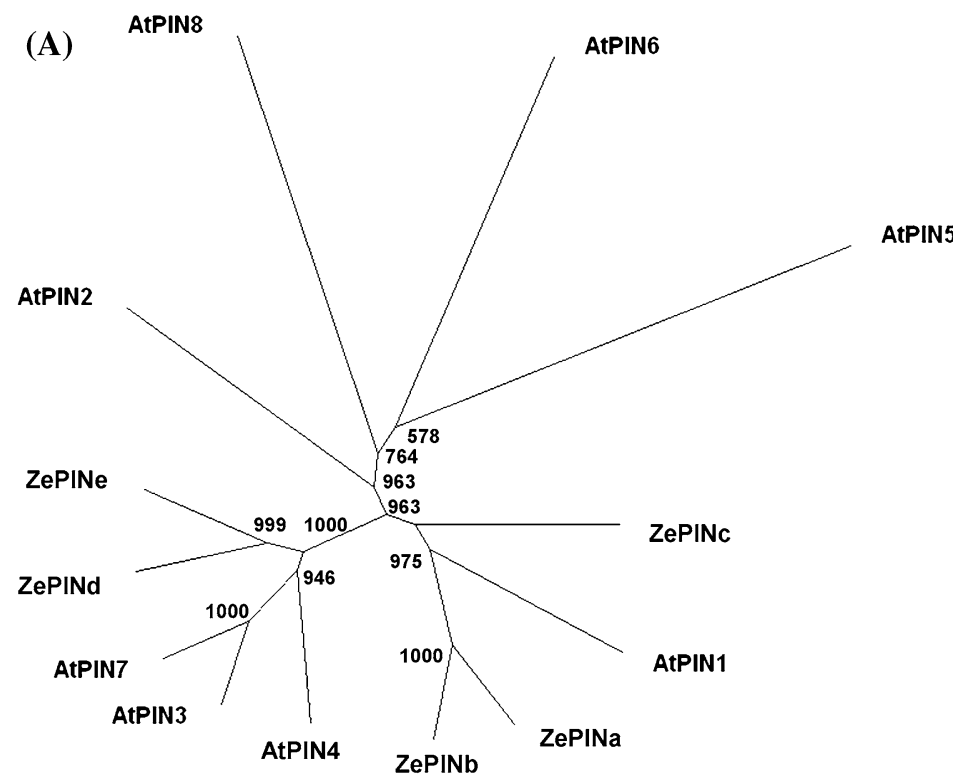

(B)

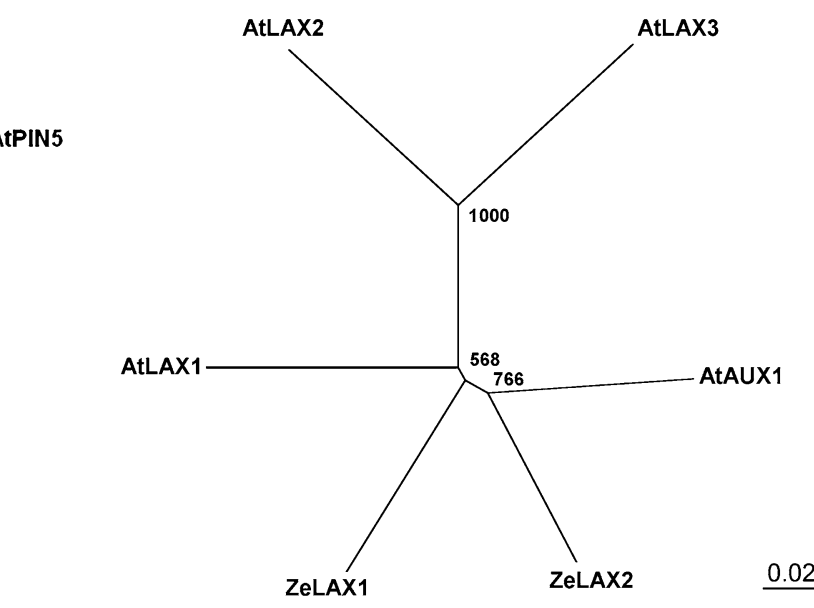

0.1

Fig. 3 Phylogenic trees of auxin carrier proteins. Phylogenic trees of auxin efflux (a) and auxin influx carrier (b) proteins. Unrooted phylogenetic trees were drawn using the full-length sequences of proteins. ClustalX and Njplot software were used for protein alignment and construction of the relationship trees, respectively. Numbers indicate the bootstrap values
Fig. 4 RT-PCR analysis of Zinnia auxin carrier gene homologues. Changes in the accumulation of mRNAs for ZeLAX1 (a), ZeLAX2 (b), ZePINa (c), ZePINb (d) ZePINc (e), ZePINd (f), and ZePINe (g). RT-PCR analyses were performed by using total RNAs prepared from isolated Zinnia mesophyll cells $(0 \mathrm{~h})$, cells cultured for $60 \mathrm{~h}$ in $\mathrm{D}$ medium $(60 \mathrm{~h} \mathrm{D})$, cells cultured for $60 \mathrm{~h}$ with NPA (60 h NPA), cells cultured for the indicated time periods with NAA or DMSO after $60 \mathrm{~h}$ culture with NPA (NPA + NAA/DMSO, 0.7, 4, $12 \mathrm{~h}$ ). The data represent the average of relative expression levels to ZeTUA5 in three independent experiments
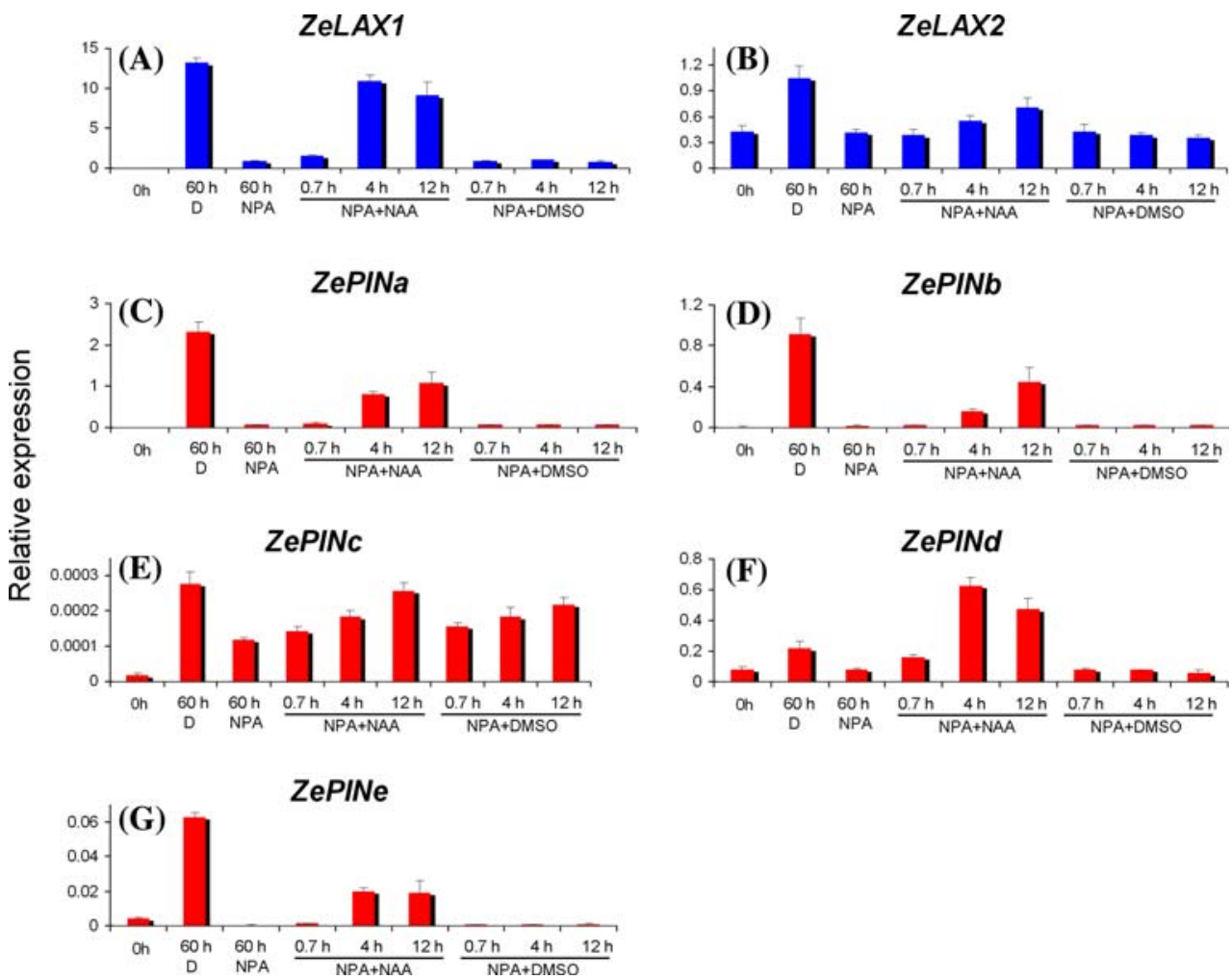

Expression profiles of brassinosteroid (BR), cytokinin and gibberellin (GA)-related gene homologues

BR and cytokinin are essential hormones for vascular differentiation (Fukuda 2004). Therefore, we examined the expression pattern of BR and cytokinin-related genes after NAA-treatment (Fig. 5a, b; Supplemental Table 5). From Zinnia, many BR biosynthesis-related cDNAs have been isolated (Yamamoto et al. 2001). Yamamoto indicated that most of such BR biosynthesis-related genes were 
up-regulated in association with the progress of stage 2. Of these genes, only $\mathrm{Ze} D W F 4$, which catalyzes a key step of BR biosynthesis (Yamamoto et al. 2007), was up-regulated significantly after $4 \mathrm{~h}$ of NAA addition (Fig. 5a). The expression of other BR-biosynthesis-related genes including ZeDWARF rather decreased after NAA-treatment. Transcripts for Z2312, which is a BAS1 gene encoding a BR inactivating enzyme (Neff et al. 1999; Turk et al. 2003), were also decreased by NAA. On the other hand, the expression of BR signaling-related genes was not much affected by NAA addition (Fig. 5a).

Cytokinin signaling-related genes were not significantly affected by NAA either, although some genes seemed to be down-regulated by NAA treatment (Fig. 5b; Supplemental Table 5). In contrast, the expression of a cytokinin oxidase gene homologue (Z4008, CKX; Werner et al. 2003) was strongly expressed $4 \mathrm{~h}$ after NAA addition and kept high levels thereafter, suggesting that auxin may activate cytokinin oxidase and consequently reduce cytokinin levels in the early stage of TE differentiation (Fig. 5b). We will describe the further analysis of the relationship between auxin and cytokinin oxidase genes below.

It has been suggested that GA may be involved in TE differentiation (Kuriyama and Fukuda 2001; Tokunaga et al. 2006). In our result, the expression of a GA biosynthesis gene, a KAO2 homologue (Z606; Helliwell et al.

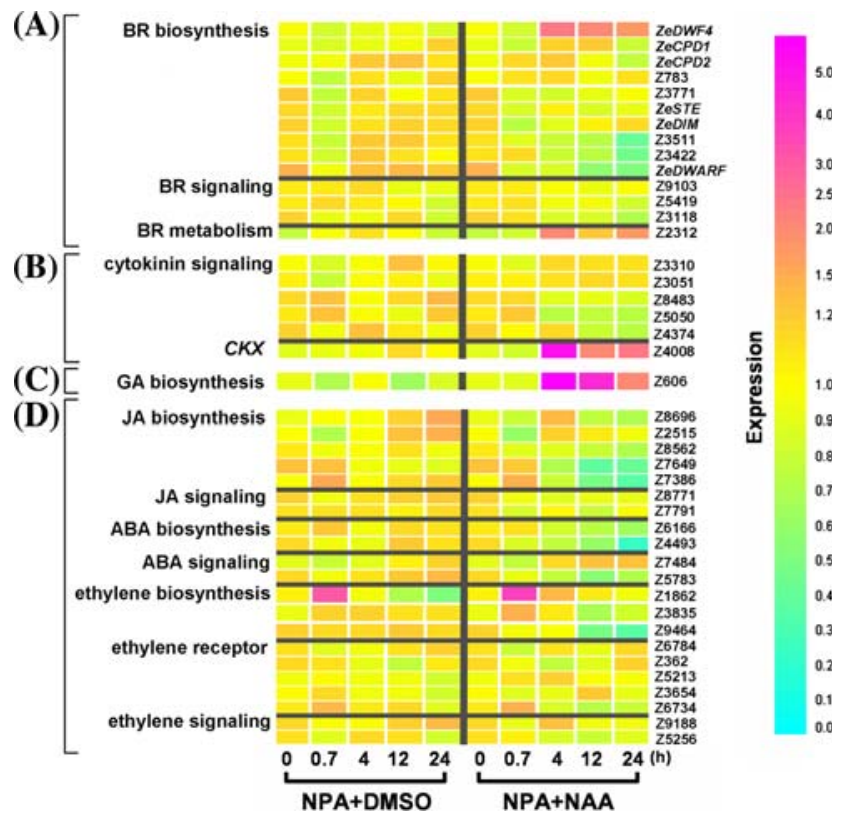

Fig. 5 Expression profiles of hormone-related gene homologues. Gene expression patterns of BR-related gene homologues (a), cytokinin-related gene homologues (b), GA-related gene homologues (c), JA, ABA, and ethylene-related gene homologues (d) in cells cultured with only NPA (NPA + DMSO) and NPA plus NAA (NPA + NAA). The color scale indicates the expression levels. The results of BLASTX search of each clone against Arabidopsis database are shown in Supplemental Table 5
2001) was significantly up-regulated $4 \mathrm{~h}$ after the NAA addition (Fig. 5c; Supplemental Table 5).

Expression profiles of jasmonic acid (JA), abscisic acid (ABA) and ethylene-related gene homologues

The expression of genes that are possibly associated with JA biosynthesis (Z8696, Z8562, Z7649, and Z7386) and JA signaling (Z8771 and Z7791) was suppressed by NAA treatment (Fig. 5d; Supplemental Table 5). Because most of these genes are expressed in stage $1(0$ and/or $24 \mathrm{~h}$ in control D-culture), this result is consistent with the idea that NAA suppresses the further progression of stage 1. Similarly, cDNAs with homologies to ABA biosynthesis-related genes (Z4493 and Z6166), and to an ABA-responsive elementbinding protein AREB2 (Z5783; Uno et al. 2000) were down-regulated by NAA addition (Fig. 5d; Supplemental Table 5). NAA did not much affect genes related to ethylene biosynthesis and signaling, except a 2-oxoglutarate-dependent dioxygenase homologue (Z9464; Trentmann and Kende 1995), which was down-regulated by NAA addition (Fig. 5d; Supplemental Table 5).

Expression analysis of Arabidopsis cytokinin oxidase genes

As mentioned above, we found that NAA promoted the expression of a $C K X$ gene. To investigate the regulation

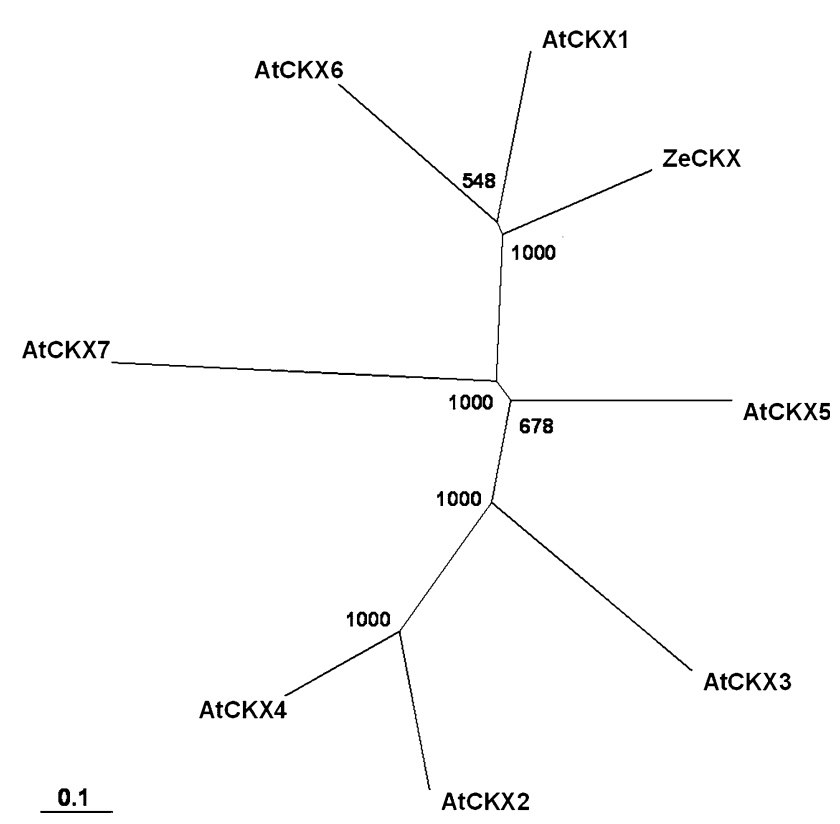

Fig. 6 Phylogenic tree of CKX proteins. A phylogenic tree of CKX proteins. An unrooted phylogenetic tree was drawn using the fulllength sequences of proteins. ClustalX and Njplot software were used for protein alignment and construction of the relationship tree, respectively. Numbers indicate the bootstrap values 
mechanism of cytokinin oxidase during transdifferentiation into TEs, we isolated a full length cDNA of Zinnia CKX. Deduced amino acid sequence of ZeCKX was highly homologous to those of Arabidopsis CKX1 (At2g41510) and CKX6 (At3g63440; Fig. 6).

Therefore, we studied the spatial expression pattern and auxin response of Arabidopsis $C K X 1$ and $C K X 6$ using promoter::GUS fusion constructs in Arabidopsis (Werner et al. 2003). AtCKX1::GUS plants did not show detectable levels of GUS activity even when treated with IAA. Three-day old seedlings harboring AtCKX6::GUS were treated with or without $10 \mu \mathrm{M}$ IAA for $6 \mathrm{~h}$ in liquid medium (Fig. 7). In non-treated seedlings, weak AtCKX6::GUS expression was detected in the procambium (Fig. 7a, c, e). IAA treatment enhanced the GUS activity in the procambium (Fig. 7b, d, f). $G U S$ expression was also observed in stomata of mature leaves. However, auxin treatment did not strongly influence the GUS activity in stomata (data not shown). These results supported our data from cell culture experiment showing that auxin promotes the expression of a cytokinin oxidase gene specifically in the procambium and/or developing TEs.

\section{Discussion}

Auxin promotes an early transdifferentiation process in vascular differentiation

Auxin is necessary for transdifferentiation into TEs in Zinnia culture system. However, it is not known yet how and when auxin works in TE differentiation. The result of our microarray analysis implies that auxin acts at the transition from stage 1 to 2 of TE differentiation. Auxin may act during the transdifferentiation process to repress wound response and promote early vascular differentiation.

We also found that in the entry into stage 2, auxin regulated the expression of a number of genes at an early stage of TE differentiation. As early up-regulated genes, we identified 149 cDNAs, which included genes for proteins related to hormone biosynthesis, metabolism, methylation, redox, transport, and transcription factors.

Genes that were expressed within $4 \mathrm{~h}$ after NAA treatment included three genes, Z567, ZeHB10, and ZeHB13 (Z3685) encoding well-known transcription factors. Kubo et al. (2005) found VASCULAR-RELATED NAC-DOMAIN PROTEINs (VND1-VND7), which are NAC-domain transcription factors, expressed in association with vascular differentiation in Arabidopsis. Overproduction and suppression of VND6 and VND7 demonstrated that these genes are master genes inducing differentiation into metaxylem TEs and protoxylem TEs, respectively. Zinnia Z567 is homologous to $V N D$ s, especially to $V N D 1, V N D 2$, and $V N D 3$. Promoter analysis indicated that $V N D 1-V N D 3$ are expressed preferentially in procambial cells next to the quiescent center (Kubo et al. 2005).

It has been known that the differentiation of xylem cells from procambial cells is coupled with the gradual expression of HD-ZIPIII homeobox genes (Ohashi-Ito et al. 2002, 2005; Ohashi-Ito and Fukuda 2003): mRNA for ZeHB13 (corresponding to $A t H B 15$ ) accumulates in procambial and xylem precursor cells and mRNAs for ZeHBIO (corresponding to $A t H B 8$ ) accumulates highly in xylem precursor cells and developing TEs. AtHB15 and AtHB8 are also expressed strictly in vascular bundles, in particular, in the procambial or xylem precursor region (Baima et al. 1995; Kang and Dengler 2002; Ohashi-Ito and Fukuda 2003).

Thus the finding that NAA induces the homologue of $V N D s, \mathrm{ZeHB} 10$, and $\mathrm{ZeHB} 13$ within $4 \mathrm{~h}$, demonstrates that auxin is a very early, if not direct, factor initiating vascular cell differentiation.

Possible members of auxin signal transduction factors in early vascular development

The microarray analysis also showed that various genes involved in auxin-signal transduction or metabolism were up-regulated by NAA addition. In our experiment, three members of the Aux/IAA family, IAA4 homologues (Z824 and Z1689), an IAA13 homologue (Z3615) and an IAA9 homologue (Z2172) were expressed after $0.7 \mathrm{~h}$ of NAA application, while another member was induced more slowly by NAA, suggesting that not all but a limited number of $A u x / I A A$ family members are expressed at the transition from stage 1 to 2 . Groover et al. (2003) showed that $z I A A 8$, which is a Zinnia homologue of Arabidopsis IAA 8 and IAA9, was expressed preferentially in primary vasculature in seedlings. Therefore, Z2172 and probably Z824, Z1689, and Z3615 may also act in early vascular differentiation, although we cannot exclude the possibility that these genes are induced in all cell types by auxin. On the other hand, our Zinnia microarray contained nine cDNAs with similarity to $A R F$ family genes. Of these genes, ARF4 homologues (Z8416 and Z3670) and a MONOPTEROS (MP) homologue (Z1496) were up-regulated after $4 \mathrm{~h}$ of NAA addition. Mutations in $M P$ interfere with the formation of vascular strands at all stages (Berleth and Jürgens 1993). Therefore, the ARF4 proteins as well as $M P$ might be involved in early auxin signaling, directing vascular cell differentiation together with the vascular tissue-related Aux/IAA family members.

Positive-feedback of auxin may promote vascular differentiation

The "auxin flow canalization hypothesis", has suggested that auxin flow which starts initially by diffusion, induces 
Fig. 7 AtCKX6::GUS expression patterns. Three-dayold AtCKX6::GUS seedlings were treated with $(\mathbf{b}, \mathbf{d}, \mathbf{f})$ or without $(\mathbf{a}, \mathbf{c}, \mathbf{e}) 10 \mu \mathrm{M}$ IAA for $6 \mathrm{~h}$ in liquid medium. Whole plant $(\mathbf{a}, \mathbf{b})$, cotyledon $(\mathbf{c}, \mathbf{d})$, and root (e, f). Arrowheads indicate developing TEs $(\mathbf{c}-\mathbf{f})$. DIC Images are shown. The bars represent $100 \mu \mathrm{m}$
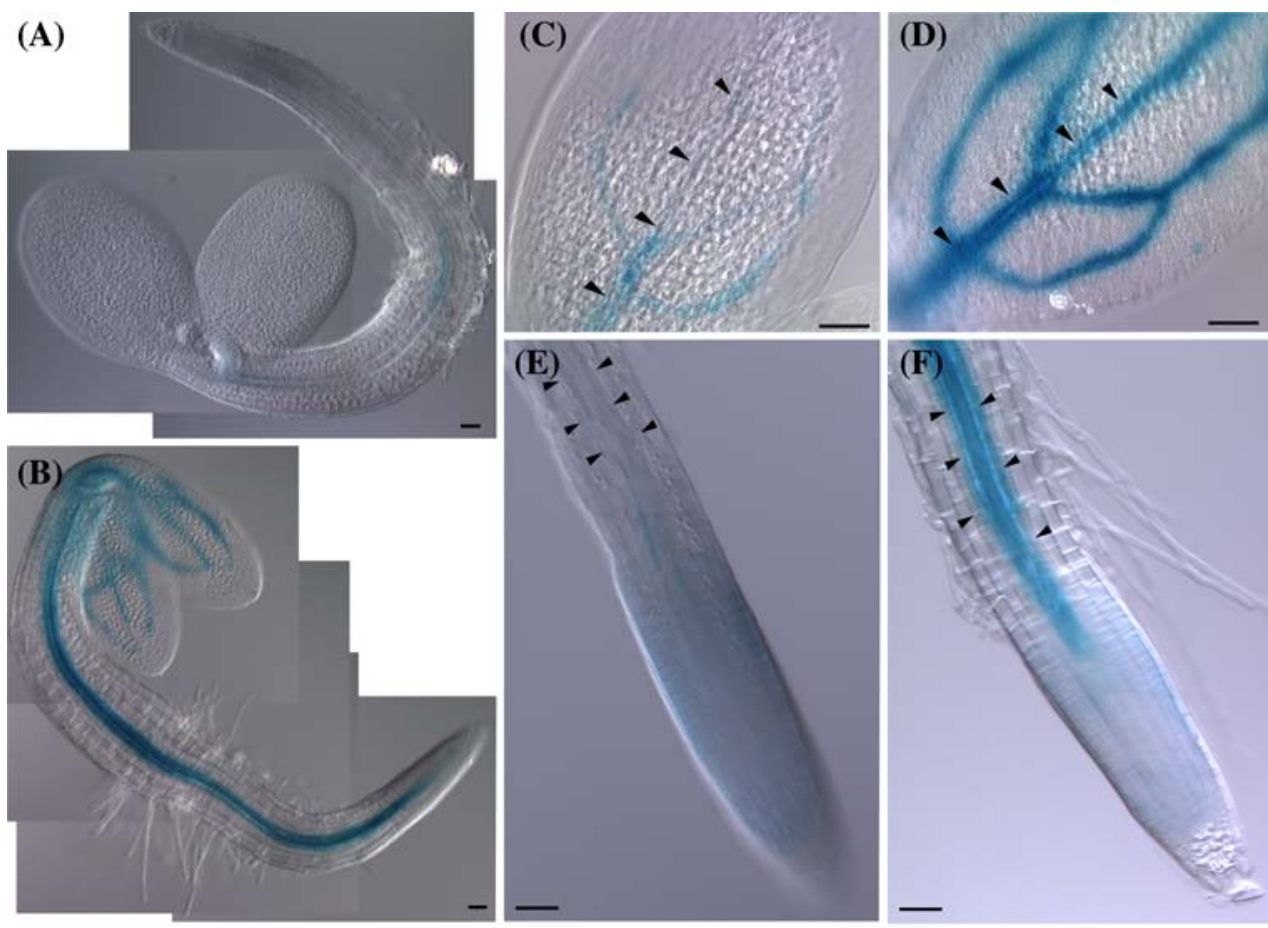

$100 \mu \mathrm{m}$

the formation of polar auxin transport cell system, which in turn promotes auxin transport, leading to canalization of auxin flow along a narrow file of cells (Sachs 2000). This continuous polar transport of auxin through cells finally results in the differentiation of strands of procambial cells and then vascular strands. This hypothesis predicts a positive feed back mechanism that stimulates auxin conductivity within preferred routes of auxin transport (Berleth and Mattsson 2000). Recent studies indicated that auxindependent localization of PIN1 protein is a component of the positive feedback loop to form vascular strands (Scarpella et al. 2006). It has been suggested that AUX1 and PIN1 work together and restrict auxin flow in developing tissues (Reinhardt et al. 2003; Bainbridge et al. 2008). In this study, we demonstrated that most genes encoding auxin influx and efflux carrier proteins were rapidly up-regulated in xylogenic Zinnia culture cells by NAA. Therefore, an auxindependent transcriptional activation of the genes for auxin influx and efflux carriers may also function as a component of positive feedback loop of polar auxin transport predicted in the auxin flow canalization hypothesis. An unsolved important question is if these carrier proteins are necessary for differentiation into procambial cells and/or xylem cells.

Auxin affects various hormonal events during TE differentiation

Auxin also affected expression of genes related to various plant hormones on our microarray. Not all but many genes related to biosynthesis and signaling of $\mathrm{ABA}$ and $\mathrm{JA}$ were repressed by NAA addition. Because $\mathrm{ABA}$ and JA are known as wound-related hormones, NAA may function in healing of wound due to the preparation of mesophyll cells.

Yamamoto et al. (1997, 2001) showed that BRs are synthesized actively during stage 2 , and are necessary for differentiation of procambial cells to xylem cell precursors and/or of xylem cell precursors to TEs and xylem parenchyma cells (Fukuda 2004). An active BR, brassinolide (BL) is biosynthesized by various enzymes including many P450 proteins. One of them DWF4, is a cytochrome P450 mediating the $22 \alpha$-hydroxylation to produce 6-Deoxocathasterone (6-DeoxoCT) and cathasterone (CT), and is a key enzyme of BR biosynthesis (Choe et al. 1998). We found that Zinnia DWF4 (ZeDWF4) was greatly up-regulated $4 \mathrm{~h}$ after the addition of NAA, while other BR biosynthetic genes were not induced significantly by NAA. Rather, a Zinnia homologue of DWARF, which encodes another P450 enzyme catalyzing a final step of castasterone (CS) and BL biosynthesis, was repressed after NAA addition. Interestingly, BAS1, which encodes a cytochrome P450 involved in the inactivation of BL and CS (Neff et al. 1999; Turk et al. 2003), was up-regulated $4 \mathrm{~h}$ after of NAA addition. These results suggest that auxin promotes the biosynthesis of BL intermediates, but suppresses BL biosynthesis and inactivates BL. This suggestion is consistent with the fact that in stage 2, BL intermediates accumulate but the levels of CS and BL are quite low (Yamamoto et al. 2001). The low levels of active BRs may function to 
suppress an immediate differentiation into TEs. Thus, auxin may regulate BR levels in a sophisticated manner.

A GA synthesis-related gene is up-regulated rapidly by NAA. Previous studies indicated that GA promotes lignification by activating the polymerization of lignin precursors in Zinnia culture system (Tokunaga et al. 2006). Therefore, this result suggests that auxin may enhance lignification during TE differentiation through up-regulation of GA biosynthesis genes.

Cytokinin oxidase is up-regulated by auxin in vascular tissues

Cytokinins are other crucial factors for vascular differentiation (Fukuda 2004). We found that Z4008, which encodes cytokinin oxidase $(C K X)$, was up-regulated transiently $4 \mathrm{~h}$ after of NAA addition but not at $0.7 \mathrm{~h}$. Degradation of cytokinins catalyzed by cytokinin oxidase is an important mechanism by which plants modulate their cytokinin levels (Brugiere et al. 2003; Schmülling et al. 2003; Werner et al., 2003). The $C K X$ gene family in the Arabidopsis genome comprises seven members (Schmülling et al. 2003; Werner et al. 2003). Full length cDNA ( $Z e C K X)$ of Z4008 which was similar to AtCKX1 and AtCKX6.

It is reported that in $35 S:: A t C K X 1$ transgenic Arabidopsis plants, the expression of the cytokinin reporter ARR5::GUS, was reduced, indicating the enhanced cytokinin breakdown by AtCKX1 (Werner et al. 2003). Werner et al. showed that AtCKX1 was expressed in the shoot apex, lateral shoot meristems, and growing tissues of young flowers and the vascular cylinder at the site of growing lateral roots. In contrast, AtCKX6::GUS expression was mainly found in the vasculature of young growing leaves and during the maturation phase of stomatal guard cells (Schmülling et al. 2003). Our analysis revealed that AtCKX6::GUS expression was specifically localized in the procambium in leaves and expression levels were increased by auxin. This result indicates that, even in whole plants, auxin promotes the transcription of a specific $C K X(s)$ only in developing vascular cells. Therefore, cytokinin levels may decrease at the early stage of vascular differentiation mediated by auxin. Indeed Church and Galston (1988) showed that Zinnia cells required an initial $24 \mathrm{~h}$ exposure to cytokinin for TE differentiation at $72 \mathrm{~h}$ of culture, suggesting that cytokinin may be needed only during early vascular differentiation. Furthermore, Carabelli et al. (2007) showed a low R/FR light promotes DR5::GUS and AtCKX6::GUS expression in vasculature. Mähönen et al. (2006) showed that cytokinin is needed for the maintenance of the procambium but it negatively regulates protoxylem specification.

Altogether a working hypothesis may be postulated that cytokinin is needed before procambium formation and auxin induces a $C K X$ gene(s) to reduce cytokinin levels, which in turn promote further development of the procambium and/or the xylem from the procambium. Interestingly, the promoters of both AtCKX6 and AtCKX1 contain an auxin-responsive element, AuxRE in their proximal region. This fact suggests that auxin-responsive transcription of these $C K X s$ is regulated by ARFs. Further analysis is required to reveal the role of $C K X s$ as a link between auxin and cytokinin-related events in plant development.

Acknowledgments We thank Prof. Ken Matsuoka, Tomoko Narisawa, Mami Sasaki (RIKEN Plant Science Center) for technical advice of cDNA microarray; Prof. Thomas Schmülling (Free University of Berlin) for providing us $p A t C K X:: G U S$ transgenic line; Dr. Klahre Ulrich (University of Bern) for helpful comments on the manuscript; Yoichi Yokogawa for useful advice of microarray analysis. This work was supported in part by Grants-in-Aid from MEXT, Japan (19060009 to HF), and the Japan Society for the Promotion of Science (20247003 to HF).

\section{References}

Abel S, Theologis A (1996) Early genes and auxin action. Plant Physiol 111:9-17. doi:10.1104/pp.111.1.9

Baima S, Nobili F, Sessa G, Lucchetti S, Ruberti I, Morelli G (1995) The expression of the ATHB- 8 homeobox gene is restricted to provascular cells in Arabidopsis thaliana. Development 121: $4171-4182$

Bainbridge K, Guyomarc'h S, Bayer E, Swarup R, Bennett M, Mandel T, Kuhlemeier C (2008) Auxin influx carriers stabilize phyllotactic patterning. Genes Dev 22:810-823. doi:10.1101/gad. 462608

Benkova E, Michniewicz M, Sauer M, Teichmann T, Seifertova D, Jurgens G, Friml J (2003) Local, efflux-dependent auxin gradients as a common module for plant organ formation. Cell 115:591-602. doi:10.1016/S0092-8674(03)00924-3

Berleth T, Jürgens G (1993) The role of the MONOPTEROS gene in organising the basal body region of the Arabidopsis embryo. Development 118:575-587

Berleth T, Mattsson J (2000) Vascular development; tracing signals along veins. Curr Opin Plant Biol 3:406-411. doi:10.1016/ S1369-5266(00)00104-7

Berleth T, Mattsson J, Hardtke CS (2000) Vascular continuity and auxin signals. Trends Plant Sci 5:387-393. doi:10.1016/S13601385(00)01725-8

Blancaflor EB, Masson PH (2003) Plant gravitropism. Unraveling the ups and downs of a complex process. Plant Physiol 133:16771690. doi:10.1104/pp.103.032169

Blilou I, Xu J, Wildwater M, Willemsen V, Paponov I, Friml J, Heidstra R, Aida M, Palme K, Scheres B (2005) The PIN auxin efflux facilitator network controls growth and patterning in Arabidopsis roots. Nature 433:39-44. doi:10.1038/nature03184

Brugiere N, Jiao S, Hantke S, Zinselmeier C, Roessler JA, Niu X, Jones RJ, Habben JE (2003) Cytokinin oxidase gene expression in maize is localized to the vasculature, and is induced by cytokinins, abscisic acid, and abiotic stress. Plant Physiol 132:1228-1240. doi:10.1104/pp.102.017707

Carabelli M, Possenti M, Sessa G, Ciolfi A, Sassi M, Morelli G, Ruberti I (2007) Canopy shade causes a rapid and transient arrest in leaf development through auxin-induced cytokinin oxidase activity. Genes Dev 21:1863-1868. doi:10.1101/gad.432607 
Choe S, Dilkes BP, Fujioka S, Takatsuto S, Sakurai A, Feldmann KA (1998) The DWF4 gene of Arabidopsis encodes a cytochrome P450 that mediates multiple 22alpha-hydroxylation steps in brassinosteroid biosynthesis. Plant Cell 10:231-243

Church DL, Galston AW (1988) Hormonal induction and antihormonal inhibition of tracheary element differentiation in Zinnia cell cultures. Phytochemistry 27:2435-2439. doi:10.1016/0031-9422 (88)87008-0

Demura T, Tashiro G, Horiguchi G, Kishimoto N, Kubo M, Matsuoka N, Minami A, Nagata-Hiwatashi M, Nakamura K, Okamura Y, Sassa N, Suzuki S, Yazaki J, Kikuchi S, Fukuda H (2002) Visualization by comprehensive microarray analysis of gene expression programs during transdifferentiation of mesophyll cells into xylem cells. Proc Natl Acad Sci USA 99:15794-15799. doi:10.1073/pnas.232590499

Dharmasiri N, Dharmasiri S, Weijers D, Lechner E, Yamada M, Hobbie L, Ehrismann JS, Jürgens G, Estelle M (2005) Plant development is regulated by a family of auxin receptor $\mathrm{F}$ box proteins. Dev Cell 9:109-119. doi:10.1016/j.devcel.2005.05.014

Friml J (2003) Auxin transport-shaping the plant. Curr Opin Plant Biol 6:7-12. doi:10.1016/S1369526602000031

Fukuda H (1997) Tracheary element differentiation. Plant Cell 9:1147-1156. doi:10.1105/tpc.9.7.1147

Fukuda H (2004) Signals that control plant vascular cell differentiation. Nat Rev Mol Cell Biol 5:379-391. doi:10.1038/nrm1364

Fukuda H, Komamine A (1980) Establishment of an experimental system for the tracheary element differentiation from single cells isolated from the mesophyll of Zinnia elegans. Plant Physiol 65:57-60. doi:10.1104/pp.65.1.57

Fukuda H, Komamine A (1981) Relationship between tracheary element differentiation and DNA synthesis in single cells isolated from the mesophyll of Zinnia elegans-analysis by inhibitors of DNA synthesis. Plant Cell Physiol 22:41-49

Fukuda H, Komamine A (1982) Lignin synthesis and its related enzymes as markers of tracheary-element differentiation in single cells isolated from the mesophyll of Zinnia elegans. Planta 155:423-430. doi:10.1007/BF00394471

Gil P, Dewey E, Friml J, Zhao Y, Snowden KC, Putterill J, Palme K, Estelle M, Chory J (2001) BIG: a calossin-like protein required for polar auxin transport in Arabidopsis. Genes Dev 15:19851997. doi:10.1101/gad.905201

Groover AT, Pattishall A, Jones AM (2003) IAA8 expression during vascular cell differentiation. Plant Mol Biol 51:427-435. doi: 10.1023/A:1022039815537

Hagen G, Guilfoyle T (2002) Auxin-responsive gene expression: genes, promoters and regulatory factors. Plant Mol Biol 49:373385. doi:10.1023/A:1015207114117

Helliwell CA, Sullivan JA, Mould RM, Gray JC, Peacock WJ, Dennis ES (2001) A plastid envelope location of Arabidopsis entkaurene oxidase links the plastid and endoplasmic reticulum steps of the gibberellin biosynthesis pathway. Plant J 28:201208. doi:10.1046/j.1365-313X.2001.01150.x

Ito Y, Nakanomyo I, Motose H, Iwamoto K, Sawa S, Dohmae N, Fukuda $\mathrm{H}$ (2006) Dodeca-CLE peptides as suppressors of plant stem cell differentiation. Science 313:842-845. doi:10.1126/science.1128436

Kang J, Dengler N (2002) Cell cycling frequency and expression of the homeobox gene ATHB-8 during leaf vein development in Arabidopsis. Planta 216:212-219. doi:10.1007/s00425-002-0847-9

Klee H, Estelle M (1991) Morecular genetic approaches to plant hormone biology. Annu Rev Plant Physiol Plant Mol Biol 42:529-551. doi:10.1146/annurev.pp.42.060191.002525

Kubo M, Udagawa M, Nishikubo N, Horiguchi G, Yamaguchi M, Ito J, Mimura T, Fukuda H, Demura T (2005) Transcription switches for protoxylem and metaxylem vessel formation. Genes Dev 19:1855-1860. doi:10.1101/gad.1331305
Kuriyama H, Fukuda H (2001) Regulation of tracheary element differentiation. J Plant Growth Regul 20:35-51. doi:10.1007/ s003440010006

Lasswell J, Rogg LE, Nelson DC, Rongey C, Bartel B (2000) Cloning and characterization of IAR1, a gene required for auxin conjugate sensitivity in Arabidopsis. Plant Cell 12:2395-2408

Leyser O (2005) Auxin distribution and plant pattern formation: how many angels can dance on the point of PIN? Cell 121:819-822. doi:10.1016/j.cell.2005.06.005

Liscum E, Reed JW (2002) Genetics of Aux/IAA and ARF action in plant growth and development. Plant Mol Biol 49:387-400. doi: 10.1023/A:1015255030047

Mähönen AP, Bishopp A, Higuchi M, Nieminen KM, Kinoshita K, Tormakangas K, Ikeda Y, Oka A, Kakimoto T, Helariutta Y (2006) Cytokinin signaling and its inhibitor AHP6 regulate cell fate during vascular development. Science 311:94-98. doi: 10.1126/science. 1118875

Mattsson J, Sung ZR, Berleth T (1999) Responses of plant vascular systems to auxin transport inhibition. Development 126:2979-2991

Mattsson J, Ckurshumova W, Berleth T (2003) Auxin signaling in Arabidopsis leaf vascular development. Plant Physiol 131:13271339. doi:10.1104/pp.013623

Motose H, Sugiyama M, Fukuda H (2004) A proteoglycan mediates inductive interaction during plant vascular development. Nature 429:873-878. doi:10.1038/nature02613

Neff MM, Nguyen SM, Malancharuvil EJ, Fujioka S, Noguchi T, Seto H, Tsubuki M, Honda T, Takatsuto S, Yoshida S, Chory J (1999) BAS1: A gene regulating brassinosteroid levels and light responsiveness in Arabidopsis. Proc Natl Acad Sci USA 96:15316-15323. doi:10.1073/pnas.96.26.15316

Ohashi-Ito K, Fukuda H (2003) HD-Zip III homeobox genes that include a novel member, ZeHB-13 (Zinnia)/ATHB-15 (Arabidopsis), are involved in procambium and xylem cell differentiation. Plant Cell Physiol 44:1350-1358. doi:10.1093/pcp/pcg164

Ohashi-Ito K, Demura T, Fukuda H (2002) Promotion of transcript accumulation of novel Zinnia immature xylem-specific HD-Zip III homeobox genes by brassinosteroids. Plant Cell Physiol 43:1146-1153. doi:10.1093/pcp/pcf135

Ohashi-Ito K, Demura T, kubo M, Fukuda H (2005) Class III homeodomain leucine-zipper proteins regulate xylem cell differentiation. Plant Cell Physiol 46:1646-1656. doi:10.1093/pcp/ pci180

Ozeki Y, Masui K, Sakuta M, Matsuoka M, Ohashi Y, KanoMurakami Y, Yamamoto N, Tanaka Y (1990) Differential regulations of phenylalanine ammonia-lyase genes during anthocyanin synthesis and by transfer effect in carrot cell suspension cultures. Physiol Plant 80:379-387. doi:10.1034/ j.1399-3054.1990.800308.x

Reinhardt D, Pesce ER, Stieger P, Mandel T, Baltensperger K, Bennett M, Traas J, Friml J, Kuhlemeier C (2003) Regulation of phyllotaxis by polar auxin transport. Nature 426:255-260. doi: 10.1038 /nature 02081

Sachs T (1981) The control of the patterned differentiation of vascular tissues. Adv Bot Res 9:152-262

Sachs T (1991) Cell polarity and tissue patterning in plants. Development 91:83-93

Sachs T (2000) Integrating cellular and organismic aspects of vascular differentiation. Plant Cell Physiol 41:649-656

Scarpella E, Marcos D, Friml J, Berleth T (2006) Control of leaf vascular patterning by polar auxin transport. Genes Dev 20:1015-1027. doi:10.1101/gad.1402406

Schmulling T, Werner T, Riefler M, Krupkova E, Bartrina Y, Manns I (2003) Structure and function of cytokinin oxidase/dehydrogenase genes of maize, rice, Arabidopsis and other species. J Plant Res 116:241-252. doi:10.1007/s10265-003-0096-4 
Sieburth LE (1999) Auxin is required for leaf vein pattern in Arabidopsis. Plant Physiol 121:1179-1190. doi:10.1104/pp.121.4.1179

Teale WD, Paponov IA, Palme K (2006) Auxin in action: signalling, transport and the control of plant growth and development. Nat Rev Mol Cell Biol 7:847-859. doi:10.1038/nrm2020

Tokunaga N, Uchimura N, Sato Y (2006) Involvement of gibberellin in tracheary element differentiation and lignification in Zinnia elegans xylogenic culture. Protoplasma 228:179-187. doi: 10.1007/s00709-006-0180-4

Trentmann SM, Kende H (1995) Analysis of Arabidopsis cDNA that shows homology to the tomato E8 cDNA. Plant Mol Biol 29:161-166. doi:10.1007/BF00019127

Turk EM, Fujioka S, Seto H, Shimada Y, Takatsuto S, Yoshida S, Denzel MA, Torres QI, Neff MM (2003) CYP72B1 inactivates brassinosteroid hormones: an intersection between photomorphogenesis and plant steroid signal transduction. Plant Physiol 133:1643-1653. doi:10.1104/pp.103.030882

Uno Y, Furihata T, Abe H, Yoshida R, Shinozaki K, YamaguchiShinozaki K (2000) Arabidopsis basic leucine zipper transcription factors involved in an abscisic acid-dependent signal transduction pathway under drought and high-salinity conditions. Proc Natl Acad Sci USA 97:11632-11637. doi:10.1073/pnas. 190309197

Wenzel CL, Hester Q, Mattsson J (2008) Identification of genes expressed in vascular tissues using NPA-induced vascular overgrowth in Arabidopsis. Plant Cell Physiol 49:457-468. doi: 10.1093/pcp/pcn023
Werner T, Motyka V, Laucou V, Van Smets R, Onckelen H, Schmulling T (2003) Cytokinin-deficient transgenic Arabidopsis plants show multiple developmental alterations indicating opposite functions of cytokinins in the regulation of shoot and root meristem activity. Plant Cell 15:2532-2550. doi:10.1105/ tpc. 014928

Yamamoto R, Demura T, Fukuda H (1997) Brassinosteroids induce entry into the final stage of tracheary element differentiation in cultured Zinnia cells. Plant Cell Physiol 38:980-983

Yamamoto R, Fujioka s, Demura T, Takatsuto S, Yoshida S, Fukuda $\mathrm{H}$ (2001) Brassinosteroid levels increase drastically prior to morphogenesis of tracheary elements. Plant Physiol 125:556563. doi:10.1104/pp.125.2.556

Yamamoto R, Fujioka S, Iwamoto K, Demura T, Takatsuto S, Yoshida S, Fukuda H (2007) Co-regulation of brassinosteroid biosynthesis-related genes during xylem cell differentiation. Plant Cell Physiol 48:74-83. doi:10.1093/pcp/pcl039

Yazaki J, Kishimoto N, Nakamura K, Fujii F, Shimbo K, Otsuka Y, Wu J, Yamamoto K, Sakata K, Sasaki T, Kikuchi S (2000) Embarking on rice functional genomics via cDNA microarray: use of $3^{\prime}$ UTR probes for specific gene expression analysis. DNA Res 7:367-370. doi:10.1093/dnares/7.6.367

Yoshida S, Kuriyama H, Fukuda H (2005) Inhibition of transdifferentiation into tracheary elements by polar auxin transport inhibitors through intracellular auxin depletion. Plant Cell Physiol 46:2019-2028. doi:10.1093/pcp/pci217 